\title{
Scleral buckling for retinal detachment in Ibadan, Sub-Saharan Africa: anatomical and visual outcome
}

This article was published in the following Dove Press journal:

Clinical Ophthalmology

30 May 2013

Number of times this article has been viewed

\section{TS Oluleye \\ OA Ibrahim \\ BA Olusanya}

Retina and Vitreous Unit, Department of Ophthalmology, University College Hospital, Ibadan, Nigeria
Correspondence: TS Oluleye Department of Ophthalmology, University College Hospital, PMB 5I I6, Ibadan, Nigeria Email t_oluleye@yahoo.co.uk
Background: Scleral buckle surgery is not a commonly performed surgical procedure in Sub-Saharan Africa due to a paucity of trained vitreo retinal surgeons. The aim of the study was to review sclera buckle procedures with a view to evaluating the anatomical and visual outcomes.

Methods: Case records of patients that had scleral buckle surgery at the Retina Unit of the University College Hospital, Ibadan, Nigeria, between 2007 and 2010 were reviewed. Information retrieved included patients' demographics, duration of symptoms, and presenting vision. Other information included site of retinal break, extent of retinal detachment, involvement of the fellow eye, and macular involvement. Postoperative retina reattachment and postoperative visual acuity were also recorded. Proportions and percentages were used to analyze data.

Results: Forty five eyes of 42 patients were studied with a male to female ratio of 1.6:1. The mean age was 47.7 years ( \pm 17.6 years). The median duration before presentation was 3 months (range: 5 days - 156 months). Subtotal retinal detachment was found in 35 eyes (77.8\%) while total retinal detachment occurred in ten eyes $(22.2 \%)$. Thirty four eyes $(75.6 \%)$ had "macular off" detachments. At 6 weeks, there was an improvement in visual acuity in 23 eyes (51.1\%), while visual acuity remained the same in nine eyes (20\%) and was worse in 13 eyes (28.9\%). Anatomical attachment was seen in 43 eyes $(95.6 \%)$ on the operation table, in 40 eyes $(90.9 \%)$ at first day postoperatively and in 32 eyes $(86.5 \%)$ at 6 weeks after surgery.

Conclusion: Outcome of sclera buckle surgery for rhegmatogenous retinal detachment may be improved in developing countries of Sub Sahara Africa if adequate awareness is created to educate the populace on early presentation.

Keywords: retinal detachment, scleral buckle surgery, anatomical and visual outcomes, Ibadan

\section{Introduction}

Scleral buckling is one of the most established techniques for the treatment of primary rhegmatogenous retinal detachment. Jules Gonin performed the first successful retinal detachment surgery after accurate localization of retinal breaks, drainage of subretinal fluid and thermo cautery. ${ }^{1}$ He presented his work to the Swiss Ophthalmology Society and laid the foundation for retinal detachment surgery. ${ }^{2}$ Ernst Custodis performed the first sclera buckle surgery. ${ }^{3}$ Charles Schepens developed the indirect ophthalmoscope with sclera depressor and performed the first buckling surgery in the United States ${ }^{4}$ while Harvey Lincoff introduced the silicone sponge and modern cryotherapy. 5,6

The scleral buckling procedure has resulted in improved vision especially when it is performed in fresh retinal detachment..$^{7-9,11,12}$ In the developing countries like Nigeria, 
resources are scarce and vitrectomy facilities are not readily available. Scleral buckling surgeries give hope to people with rhegmatogenous retinal detachment.

The aim of this study is to highlight the anatomical and visual outcomes of scleral buckle in relation to the pattern of presentation of rhegmatogenous retinal detachment at the University College Hospital (UCH), Ibadan, Nigeria.

\section{Material and methods}

This is a retrospective interventional case series of all patients who had scleral buckling surgeries done at the Retina and Vitreous Unit of the Department of Ophthalmology, University College Hospital, Ibadan, Nigeria, from October 2007 to May 2010. Information retrieved from the case records include sociodemographic data, source of referral, site of retinal breaks, macular involvement, involvement of fellow eye, visual acuity (VA) at pre -and post-scleral buckle surgery, anatomical success of the procedure, visual outcome, complications, and reoperations.

Scleral buckle surgery in our center is mostly performed under local anesthesia in adults with general anesthesia used for children. The procedure included conjunctiva peritomy, recti muscle bridle sutures, localization of breaks with indirect ophthalmoscopy and cryotherapy to retinal breaks. Scleral anchor sutures using spatulated 5-0 dacron sutures (Ethicon, Johnson \& Johnson, New Brunswick, NJ, USA) are applied over the retinal breaks. Silicone or rubber sponges are then applied. Subretinal fluid drainage is done in eyes with bullous retinal detachments and long standing detachments with a 25 gauge needle close to the horizontal meridian. Air is injected into the vitreous cavity in eyes with superior breaks. Anatomical (attachment) success was defined as the apposition of the sensory retina to the retinal pigment epithelium. This was checked on the table, at discharge and at 6 weeks. Good visual outcome was defined as improvement in VA of at least two lines using the illuminated Snellen's chart at 6 weeks. Fair visual outcome was defined as improvement in Snellen VA of one line. Fellow eye involvement was defined as the presence of features predisposing to retinal detachment seen in the other eye, such as retinal breaks or tears and lattice degeneration.

\section{Results}

Forty two patients were analyzed with a male to female ratio of 1.6:1. Forty five eyes of these 42 patients had surgeries and were studied. All the patients had phakic retinal detachments. Three patients had bilateral retinal detachment (one male, two female). Fifty one percent (23 eyes) had left eye surgeries while $48.9 \%$ (22) of surgeries were performed on right eyes. The patients' ages ranged between 11-79 years (mean: 47.7 years, standard deviation \pm 17.6 years).

The median duration before presentation was 3 months ( 5 days -156 months) and the median duration between presentation and surgery was also 3 months ( 1 day -5 months). Twenty four people (53.3\%) were referred from private eye clinics. Twenty one eyes $(46.7 \%)$ had retinal breaks located at the superotemporal quadrant, $13(28.9 \%)$ had breaks in the inferotemporal quadrant and eight eyes (17.8\%) had retinal breaks in the inferonasal quadrant. Superonasal quadrant break was found in one eye. One patient had breaks in both the superotemporal and superonasal quadrants. In one eye, the break could not be found but the probable site was suspected by the Lincoff's rule. Thirty two eyes $(72.7 \%)$ had horseshoe tears while ten eyes had atrophic holes $(22.7 \%)$. Two eyes $(4.6 \%)$ had giant retina tears. The fellow eye had pathological changes that may predispose to retinal detachment in $38 \%$ of the studied patients, while lens opacity was present in 19 eyes (42.2\%). Subtotal retinal detachment was found in 35 eyes $(77.8 \%)$ while total retinal detachment occurred in ten eyes $(22.2 \%)$. Thirty four eyes $(75.6 \%)$ had "macular off" detachments while eleven eyes (24.4\%) did not have macular involvement. Sponge plus an encirclement band were used in 27 eyes (60\%) while 18 eyes (40\%) had sponge alone applied to close the breaks. Subretinal fluid (SRF) drainage was done in $38(84.4 \%)$ eyes.

Postoperative complications seen included raised intraocular pressure in five eyes. Reoperation occurred in five eyes due to the reopening of breaks from proliferative vitreo retinopathy (PVR).

At presentation, 24 eyes $(53.3 \%)$ had VA $<3 / 60$, ten eyes $(22.2 \%)$ had VA between $6 / 18$ and $3 / 60$, and eleven eyes $(24.4 \%)$ had VA $>6 / 18$. However, the proportion of patients with VA $\geq 3 / 60$ increased from $47.7 \%$ pre-operatively to $59.1 \%$ on the first post-operative day $(P=0.008)$ and the proportion of patients with $\mathrm{VA} \geq 3 / 60$ increased to $66.7 \%$ by 6 weeks after surgery $(P=0.005)$ (Table 1$)$.

With regards to visual outcome at 6 weeks, there was an improvement in VA in 23 eyes (51.1\%), while VA remained

Table I Visual outcome of scleral buckle surgery in Ibadan, Sub-Saharan Africa

\begin{tabular}{llll}
\hline $\begin{array}{l}\text { Visual acuity } \\
\text { category }\end{array}$ & $\begin{array}{l}\text { Preoperative } \\
\text { (\%) }\end{array}$ & $\begin{array}{l}\text { I day } \\
\text { postoperative } \\
\mathbf{n}(\%)\end{array}$ & $\begin{array}{l}\text { 6 weeks } \\
\text { postoperative } \\
\text { n (\%) }\end{array}$ \\
\hline$>3 / 60$ & $21(46.7)$ & $27(59.1)$ & $30(66.7)$ \\
$<3 / 60$ & $24(53.3)$ & $18(39.9)$ & $15(33.3)$ \\
Total & $45(100)$ & $45(100)$ & $45(100)$ \\
\hline
\end{tabular}


the same in nine eyes $(20 \%)$, and was worse in 13 eyes (28.9\%). Among the 23 eyes with improvement, the VA improved by one Snellen line in five $(21.7 \%)$ eyes; by two lines in ten (43.5\%) eyes; and by three or more lines in eight (34.8\%) eyes . Anatomical attachment was seen in 43 eyes $(95.6 \%)$ on the operation table, in 40 eyes $(90.9 \%)$ at first day postoperative and in 32 eyes $(86.5 \%)$ at 6 weeks post operation (Figure 1).

\section{Discussion}

This study showed that scleral buckle surgery for rhegmatogenous retinal detachment gives fairly good anatomical and visual outcomes. This is similar to previous studies in Nigeria ${ }^{7}$ and East Africa. ${ }^{8}$ Scleral buckle surgery positive outcomes are reported to be greater than 90 percent and it is appropriate for most primary rhegmatogenous retinal detachment. It is the procedure with the most documented follow up. ${ }^{9}$ The outcomes might have been better in this study. The median period of presentation was 3 months after onset of symptoms, and about two-thirds of the patients presented with "macular off" detachments. The late presentation and macular involvement are likely to have adversely affected the visual outcome. In an earlier study in Nigeria, over $90 \%$ of patients presented with "macular off" detachments. ${ }^{7}$ This is not unconnected to problems of diagnosis and late referrals. After diagnosis some of our patients still encountered delays before surgery due to financial constraints.

Encirclement was done in more than half of the cases. Most patients presented with PVR requiring encirclement. A single silicone sponge was used in the remaining cases as they had grade B or less PVR changes. Subretinal fluid drainage was performed in most cases especially in long standing cases, highly bullous detachments and the elderly with poor retina pigment epithelial (RPE) function.

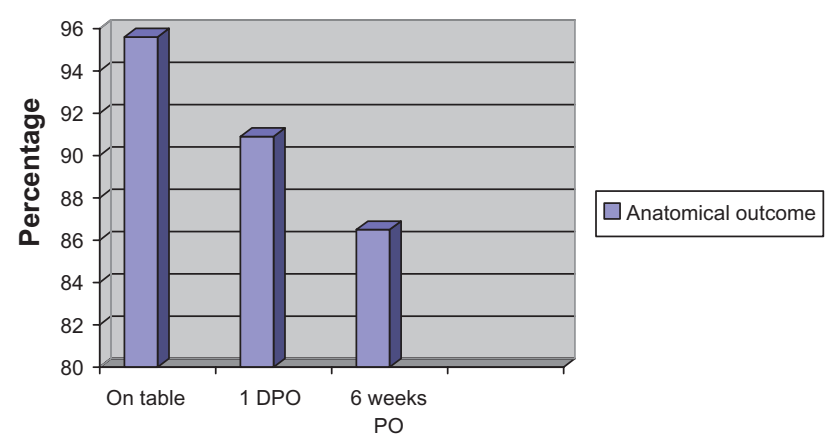

Figure I Anatomical outcome of sclera buckle surgery in Ibadan, Sub-Saharan Africa.

Abbreviations: DPO, day post-operative; PO, post-operative.
Complications of surgery included raised intraocular pressure in five patients. All the cases were controlled on topical antiglaucoma medications. Reopening of breaks was noted in five patients necessitating reoperations with buckle adjustment and reinforcement.

Retinal reattachment occurred in most patients $(95.6 \%)$ on the operating table. The proportion reduced to about $86.5 \%$ at six weeks post-operatively. The proportion with blind eyes at presentation reduced from $59 \%$ to $33 \%$ at 6 weeks post -operatively. Proliferative vitreo retinopathy may have been responsible for the poor outcome in some of the patients who presented for surgery late. Performing vitrectomy for this group of patients may have helped improve visual outcome. It has been shown that vitrectomy produces less operating time, accurate localization of holes, less refractive changes and less reoperation. ${ }^{10,12}$ Vitrectomy facilities are inadequate or unavailable in Sub-Sahara Africa. Scleral buckle surgery has also been found to be effective with studies reporting comparative results. ${ }^{11,12}$

In conclusion, scleral buckle surgery for rhegmatogenous retinal detachment may have a better outcome in developing countries of Sub-Saharan Africa if adequate awareness is created to educate the populace on early presentation. Scleral buckle surgery is advised in recent detachments with single peripheral retinal breaks. Provision of vitrectomy services may also improve the success rate of intervention especially in patients with longstanding retinal detachments.

\section{Limitations}

The study being a retrospective review is prone to problems with data retrieval. A prospective study will overcome these problems.

\section{Acknowledgments}

The assistance of the record staff of the Eye Clinic, University College Hospital, Ibadan, Nigeria in making it possible to retrieve case notes is appreciated.

\section{Disclosure}

The authors report no conflicts of interest in this work.

\section{References}

1. Gonin J. La pathologenie du decollement spontane de la retine. [The spontaneous pathology of the detachment of the retina]. Ann D'Oculist (Paris). 1904;132:230. French.

2. Gonin J. The treatment of detached retina by searing the retinal tears Arch Ophthalmol. 1930;4(5):621-625.

3. Custodis E. [Treatment of retinal detachment by circumscribed diathermal coagulation and by scleral depression in the area of tear caused by imbedding of a plastic implant]. Klin Monbl Augenheilkd Augenarztl Fortbild. 1956;129(4):476-495. German. 
4. Schepens CL. Progress in detachment surgery. Trans Am Acad Ophthalmol Otolaryngol. 1951;55:607-615.

5. Lincoff HA, Baras I, McLean J. Modifications to the Custodis procedure for retinal detachment. Arch Ophthalmol. 1965;73:160.

6. Lincoff HA, Mclean JM, Nano H. Cryosurgical treatment of retinal detachment. Trans Am Acad Ophthalmol Otolaryngol. 1964;68:412-432.

7. Alhassan MB, Rabiu MM, Olongusua Y, Ahmed A. Outcome of scleral buckling for primary rhegmatogenous retinal detachment in Nigeria. Med Sci Monit. 2005;11(12):CR589-CR593.

8. Yorston D, Jalali S. Retinal detachment in developing countries. Eye. 2002;16:353-358.

9. Schwartz SG, Kuhl DP, McPherson AR, et al. Twenty-year follow up for sclera buckling. Arch Ophthalmol. 2002;120:325-329.
10. Sharma YR, Karunanithi S, Azad RV, et al. Functional and anatomic outcome of scleral buckling versus primary vitrectomy in pseudophakic retinal detachment. Acta Ophthalmol (Scand). 2005;83:293-297.

11. Ahmadieh H, Moradian S, Faghihi H, et al. Buckling versus primary vitrectomy in pseudophakic and aphakic retinal detachment. Ophthalmology. 2005;112:1421-1429.

12. Heimann H, Bartz-Schmidt KU, Bornfeld, et al. Scleral Buckling versus Primary Vitrectomy in Rhegmatogenous Retinal Detachment Study Group. Scleral buckling versus primary vitrectomy in rhegmatogenous retinal detachment: a prospective randomized multicenter clinical study. Ophthalmology. 2007;114:2142-2154.
Clinical Ophthalmology

\section{Publish your work in this journal}

Clinical Ophthalmology is an international, peer-reviewed journal covering all subspecialties within ophthalmology. Key topics include: Optometry; Visual science; Pharmacology and drug therapy in eye diseases; Basic Sciences; Primary and Secondary eye care; Patient Safety and Quality of Care Improvements. This journal is indexed on

\section{Dovepress}

PubMed Central and CAS, and is the official journal of The Society of Clinical Ophthalmology (SCO). The manuscript management system is completely online and includes a very quick and fair peer-review system, which is all easy to use. Visit http://www.dovepress.com/ testimonials.php to read real quotes from published authors. 